\title{
XXXVIII. On the work which may be gained during the mixture of gases
}

\section{S.H. Burbury F.R.S.}

To cite this article: S.H. Burbury F.R.S. (1907) XXXVIII. On the work which may be gained during the mixture of gases, Philosophical Magazine Series 6, 14:81, 422-425, DOI: 10.1080/14786440709463698

To link to this article: http://dx.doi.org/10.1080/14786440709463698

曲 Published online: 16 Apr 2009.

Submit your article to this journal $\sqsubset \pi$

Џ Article views: 3

Q View related articles $\asymp$ 
a homogeneous beam of secondary $x$-rays may not be strictly homogeneous, for a little consideration will show that the method is not a very sensitive one for detecting the different. constituents. It is certain, however, that the secondary beams from certain substances are remarkably homogeneous in comparison with the primary.

A fuller discussion of some of the experimental results briefly referred to in this paper will be given in a paper dealing more exclusively with the theory of secondary rays when experiments which we are now engaged npon have been completed.

Note, Aug. 21, 1907.-Parker and Sexton have recently announced ('Nature,' Aug. 1, 1907) that, acting upon the suggestion of Prof. J. J. Thomson that the accepted atomic weight of cobalt was too high, they have determined it electrolytically, and have obtained as the mean of fifteen determinations the value $57 \cdot 7$. At the time that the suggestion was made by Prof. Thomson only a short preliminary notice of these results had been published, so that the published evidence was insufficient to distinguish between the possibilities of cobalt or nickel being wrongly placed. It must, however, be concluded that the first two series of experiments described in this paper point very markedly to the probability of the accepted atomic weight of nickel as being much too low. The value 59 has consequently been accepted for cobalt. (See figs. 3 and 4.)

XXXVIII. On the Work which may be gained during the Mixture of Gases. By S. H. Burbury, F.R.S.*

TN reference to my paper in the July number of this 1 Magazine, Lord Rayleigh calls my attention to a paper of his in Phil. Mag. ser. 4, vol. xlix. (1875) p. 311, with the above title. He there seeks to prove the law enunciated on p. 125 of Professor Bryan's recent work.

The problem may be stated thus :-In a horizontal tube is a mixture of two gases, say oxygen and hydrogen, the pressure of the combined gases, and also the temperature, being uniform throughout the tube. Consistently with these conditions the gases may be (1):mixed in the same relative proportions at all points in the tube, or (2) wholly or partially separated, oxygen being in greater relative density towards one end, hydrogen towards the other.

Rayleigh and Bryan maintain that to bring the mixture

* Communicated by the Author. 
from state (1) to state (2) work would have on the whole to be spent. Let then $m_{1}$ be the mass of a molecule of oxygen, $m_{2}$ that of hydrogen. And let $\overline{u_{1}^{2}}$ be the mean square of the velocity of a molecule for oxygen, $\overline{u_{2}^{2}}$ for hydrogen. Then if in an element of the tube of volume $v$, there be $n_{1}$ molecules of oxygen, $n_{2}$ of bydrogen, the total pressure, which is uniform

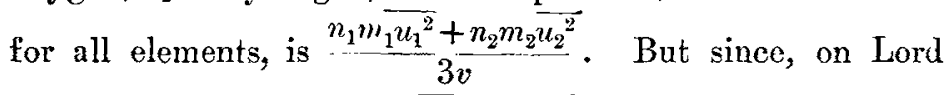
Rayloigh's authority, $m_{1} \overline{u_{1}^{2}}=m_{2} \overline{u_{2}^{2}}$, the total pressure is independent of the ratio $n_{1} / n_{2}$, solong as $n_{1}+n_{2}$ is unchanged.

From this I think it follows that we might, without doing any work, cause the hydrogen and oxygen molecules to exchange their positions by pairs in such way as to bring the mixture from state (1) to state (2). For the pressure being uniform and the tube horizontal, no forces act on the molecules, and therefore no work is done upon them, by reason of the exchanges. And the pressures are not altered by the exchanges. The process may be effected as slowly as we please. This may be an operation which with our clumsy fingers we cannot perform, but it is not an operation which essentially requires work to be spent. I then put forward the statement that in a complete cycle of operations at the end of which, as at the beginning, the tube containing the gases is horizontal and in the same position, and the total pressure $p$ uniform, but at the beginning the gases are uniformly mixed, at the end partially separated, no work is done.

It is necessary now to consider whether Lord Rayleigh has proved anything which is inconsistent with this statement. I think he has not.

At p. 314 he supposes the two gases uniformly mixed in a reservoir, the partial pressures being $\mathrm{P}_{1}$ for oxygen, $\mathrm{P}_{2}$ for hydrogen. At the top of this reservoir is a vertical tube, in which the same two gases are in equilibrium in vertical column, the pressure of the combined gases at the base being $\mathrm{P}_{1}+\mathrm{P}_{2}$, as in the reservoir. The partial pressures diminish as we ascend the tube, for oxygen more rapidly than for hydrogen. There is thus a partial separation of the gases, in addition to condensation of both gases towards the base. $\mathrm{He}$ then takes an element at the top, and compresses the gases in it till they have the combined pressure of the base, $\mathrm{P}_{1}+\mathrm{P}_{2}$. Then he brings the compressed element to the level of the base. It is proved that the work spent in the compression exceeds that gained from gravity in the descent of the element by an amount which we may call $d W$. When the same operation has been performed on every element of the tube, 
the quondam vertical column now occupies a horizontal position, in which the combined pressure of the gases is $\mathrm{P}_{1}+\mathrm{P}_{2}$ at every point, but oxygen is relatively denser at the end of the tube which was the base of the column. There has been effected a partial separation of the gases. And work $W$ has been spent on the whole. I understand Lord Rayleigh to mean that this work $W$ has been spent in the separation of the gases. It is understood that, as he suggests, we may suppose movable pistons interpolated to prevent diffusion for as long as we please.

This operation of Lord Rayleigh's is the second half of a complete cycle of which $I$ will now supply the first half. The gases to begin with are uniformly mixed in a horizontal tube $\mathrm{AB}$, and their combined pressure is $\mathrm{P}_{1}+\mathrm{P}_{2}$ at every point. Divide the tube into $\mathrm{N}$ elements each containing the same number of molecules and numbered consecutively $1 \ldots \mathrm{N}$ from $A$. Set up a model vertical column $A^{\prime} B^{\prime}$ containing the same number of molecules of each gas as $A B$, but in which the gases have attained the state of equilibrium, with $P_{1}+P_{2}$ the total pressure at the base. Divide the column into $\mathrm{N}$ elements each containing the same total number of molecules and numbered consecutively $1 \ldots N$ from the base $A^{\prime}$. To every element of the tube now corresponds an element of the column, and each contains the same number of molecules-but the proportions in which the gases are mixed are not the same in the one element as the other, nor are the volumes the same. Then, Process (1), interchange molecules of oxygen and hydrogen in the horizontal tube until each element contains the same number of molecules of either gas as the corresponding element of the column. In that process the pressure is not altered at any point, and (as I say) no work is done. Process (2), let each element of the tube expand until it has the same volume and the same pressure as the corresponding element of the column. 'The horizontal tube is now a facsimile of the vertical column, and may be set vertical without further disarrangement of the gases. It is in fact, when so set up, exactly Lord Rayleigh's vertical column, p. 314, and shall be dealt with in the way that he describes. My processes (1) and (2) constitute together the first operation of a cycle of which Lord Rayleigh performs the second. Eridently, since both my expansion and his compression take place after Process (1), the work gained in expansion is exactly equal to that spent in compression. Also since the centre of gravity of the molecules in the tube is at the end on the same level as at the beginning, no work on the whole has been done by or against gravity. Therefore, on the whole no work has been gained or spent unless it is spent in 
Process (1). But a partial separation of the gases has been effected. What Lord Rayleigh proves is therefore, if you complete the cycle, not inconsistent with the truth of my statement. What he says happens in the operation which he performs does in fact happen, but the work which, as he says, is spent was gained in the first operation of the cycle, of which he makes no mention. No work is done in the complete cycle, unless in Process (1), which consists in the passage of molecules along a level surface from the same pressure to the same pressure.

XXXIX. The Ionization Curve of Methane. By W. H. Bragg, M.A., F.R.S., Elder Professor of Mathematics and Physics in the University of Adelaide, and W. T. CoOKE, D.Sc* $\mathrm{T}^{\mathrm{T}}$ has been shown by one of us (Bragg, Phil. Mag. April 1 1907) that the loss of energy experienced by the $\alpha$ particle in crossing an atom depends, in some cases at least, on the speed of the particle. When the atom is a heavy one there is rather more loss of energy at the higher speeds. This is true of aluminium, tin, silver, and gold, in comparison with each other and with air.

It was of some importance to determine whether the principle extended to gases also, and the great difference between the weights of the $\mathrm{N}$ and $\mathrm{O}$ atoms, on the one hand, and the $\mathrm{H}$ atom on the other, seemed likely to furnish a good opportunity of settling the question. The ranges of the various a particles in hydrogen itself were too long for the apparatus at our disposal. We therefore prepared some methane $\left(\mathrm{CH}_{4}\right)$, since this gas contains a large proportion of hydrogen, and has a convenient stopping-power. The details of the preparation are given below.

The accompanying figure shows the curve which was obtained as the result of the experiment. An air curve is also drawn in the figure so as to make it easy to compare the various ranges in the two gases. The pressure and temperature of the air were adjusted so that the ranges of the $\alpha$ particle from radium itself were the same in both.

It will be seen that the ranges of the other three $\alpha$ particles do not quite correspond. The more energetic particles go further in methane than in air: thus showing that the ratio of the stopping-power of methane to that of air increases somewhat as the speed of the particle diminishes. In other words, fast $\alpha$ particles are less stopped by methane than slow ones, if air is taken as the standard of comparison. This

* Communicated"by the Authors. From "Transactions of the Royal Society of South Australia,' vol. xxxi. 1907. 